\title{
Conflicts at the heart of the FRAX tool
}

\author{
Teppo L.N. Järvinen MD PhD, Jarkko Jokihaara MD PhD, Pierre Guy MDCM MBA, Pablo Alonso-Coello MD, \\ Gary S. Collins PhD, Karl Michaëlsson MD PhD, Harri Sievänen ScD
}

A lthough the presence of osteoporosis, on average, predicts future fractures at the population level, accumulating evidence indicates that both the identification of fracture-prone individuals and the effectiveness of bone-targeted medications in preventing fractures are limited. In fact, most fractures are attributable not to osteoporosis but to falling, yet medications aimed at preventing osteoporosis are not effective in preventing falls. The suggestions by the World Health Organization (WHO) that osteoporosis is the main cause of fractures in aging populations, that bone densi tometry reliably identifies individuals at risk of fracture and that fractures can be prevented by medication at reasonable cost have all been called into question. ${ }^{1}$

In 2008, a task force led by Professor John Kanis, director of the WHO Collaborating Centre for Metabolic Bone Diseases at the University of Sheffield, with support from the International Osteoporosis Foundation, the US National Osteoporosis Foundation, the International Society for Clinical Densitometry and the American Society for Bone and Mineral Research, produced the web-based WHO fracture prediction tool called FRAX (www.shef.ac.uk/FRAX). The aim of this tool is to identify risk that is amenable to drug therapy. ${ }^{2}$ Although FRAX has now been widely adopted in clinical practice (worldwide average of about 8000 assessments daily since June 1, 2011, as recorded at the FRAX website), it does not identify fracture-prone patients any better than simpler methods of risk assessment. ${ }^{3,4}$ Furthermore, evidence that its use leads to effective targeting of drug therapy at those deemed to be at high risk of fracture is lacking. ${ }^{3,4}$

\section{Hidden methods}

In addition to the questionable evidence that FRAX improves clinical outcomes, there are serious questions as to the transparency of the tool. Most troubling is that the FRAX developers have not responded to requests for access to the underlying FRAX equations needed for independent external validation. ${ }^{4}$ This lack of access is contrary to both the general spirit of trans- parency and the standards suggested by the EQUATOR Network (www.equator-network .org), an international network that promotes transparent and accurate reporting of health research studies.

\section{Uncertain peer review of FRAX}

Since the launch of FRAX in 2008, Prof. Kanis, who was cofounder of FRAX (with Professor Eugene McCloskey), has been a coauthor on more than 50 FRAX-related papers published in Osteoporosis International, of which he is also one of the two editors-in-chief. This journal has been used as a platform to defend FRAX against studies that are critical of, fail to endorse the use of or express misgivings about the tool. Publishing FRAX articles in this manner is inconsistent with standards suggested by the Committee on Publication Ethics. ${ }^{5}$

In responding to a case involving an author who wished to submit to a journal of which he was also the editor, the Committee on Publication Ethics stipulated three main conditions: that "the choice of journals [be] limited," that "every effort [be] made to minimise any bias in the review process by having another associate editor handle the peer review procedure independently of the editor (recognising that it would be impossible to remove bias completely)," and that "the process [be] absolutely transparent." ${ }^{, 5}$ In the case of FRAX, the first proviso (limited choice of jour-

\section{- KeY POINTS}

- FRAX, the fracture risk assessment tool of the World Health Organization, was developed to improve identification of fractureprone patients and targeting of preventive pharmacotherapy, but meets neither objective.

- FRAX does not identify fracture-prone patients any better than simpler methods.

- Use of FRAX-based guidelines appears to inappropriately expand the indications for pharmacotherapy, leading to overdiagnosis and consequent overtreatment.

- Concerns have also been raised about the development and promotion of FRAX, including lack of transparency about the underlying equation, use of one codeveloper's "own journal" to promote and defend it against critique, and apparent violations of guidelines for handling conflicts of interest. 
nals) does not hold, as there are a great number of bone journals in addition to Osteoporosis International. Regarding the second and third provisos, the measures taken by Osteoporosis International to guard against the conflicts of editor as author are not reported in the published papers and will be far from transparent to most readers.

\section{Inconsistent detail in reporting conflicts of interest}

Maintaining high ethical standards for conducting and disseminating research is always important, but the imperative is even greater when high financial stakes are involved. Such is the case with the FRAX tool.

The osteoporosis field has not been free from commercial conflicts. ${ }^{6}$ In the primary FRAX publication, ${ }^{7}$ the authors (including Kanis and McCloskey) acknowledged 10 companies from the commercial private sector for "supporting the study." However, since the launch of FRAX, Kanis and McCloskey have repeatedly declared "no conflicts of interest" in their publications directly related to the tool (a recent article in $\mathrm{Cal}$ cified Tissue International ${ }^{8}$ being just one example). These declarations stand in direct contrast to Kanis and McCloskey's non-FRAX-related publications on osteoporosis, in which the developers have declared an extensive list of conflicts of interest (for examples, see Appendix 1, available at www.cmaj.ca/lookup/suppl/doi:10.1503 /cmaj.121874/-/DC1). More importantly, the declarations of competing interests in non-FRAXrelated publications also contradict the WHO guidelines for managing conflicts of interest, directed to its own guideline groups and collaborating centres, which state that to "safeguard the credibility, independence and objectivity of the work" conducted by an institution that is operating as a WHO collaborating centre, "WHO seeks to ensure that the interactions this institution may have with the commercial private sector - in particular the part of the institution being proposed for designation - do not give rise to any real or perceived conflict of interest in respect of the work of the WHO [collaborating centre]."

\section{The expanding osteoporosis market}

Inevitably, with the creation of any new predictive tool in medicine, many individuals, organizations and commercial enterprises involved in the tool's development and promotion stand to gain financially from its success. In the case of FRAX, the more people who are identified as being at risk for osteoporotic fractures and for whom drug therapy is recommended, the more certain organizations and commercial enterprises stand to gain. The US National Osteoporosis Foundation, which actively supported the development of FRAX and which is funded by pharmaceutical companies (www.nof.org/aboutnof/supportersandpartners), has released FRAX-based treatment guidelines..$^{10}$ According to an analysis by Donaldson and colleagues, ${ }^{11}$ applying these guidelines to one of the largest prospective cohort studies in osteoporosis would result in at least $72 \%$ of US white women older than 65 years and $93 \%$ of those older than 75 years being candidates for drug therapy. The FRAX developers' repeated assurances that the tool per se does not provide thresholds for intervention (thereby supposedly exonerating them from liability in terms of conflicts of interest and overdiagnosis) appear spurious, particularly given that a direct link to the intervention thresholds of the UK National Osteoporosis Guideline Group is integrated into the web page of the FRAX tool.

We believe that FRAX should be used with caution until the concerns that we have expressed in this paper are duly addressed, as follows. The founders of FRAX should release the equations that would allow for truly independent validation by external investigators; they should provide a full declaration of all potential conflicts of interest related to the FRAX tool; and they should explain in detail the obvious inconsistencies between their actions and the WHO guidelines. ${ }^{9}$ Finally, the editors of Osteoporosis International should publicly reveal the specific measures taken for the peer review process of each paper on which one or both editors were authors.

Editor's note: In the course of writing this article, the authors contacted John Kanis and Eugene McCloskey to raise the points made here, and their responses are reported in Appendix 2 (available at www.cmaj.ca/lookup/suppl/doi:10.1503 /cmaj.121874/-/DC1).

\section{References}

1. Jarvinen TL, Sievänen H, Khan KM, et al. Shifting the focus in fracture prevention from osteoporosis to falls. BMJ 2008;336: 124-6.

2. Kanis JA, Hans D, Cooper C, et al. Interpretation and use of FRAX in clinical practice. Osteoporos Int 2011;22:2395-411.

3. Rubin KH, Friis-Holmberg T, Hermann AP, et al. Risk assessment tools to identify women with increased risk of osteoporotic fracture: Complexity or simplicity? A systematic review. J Bone Miner Res 2013;28:1701-17.

4. Collins GS, Michaëlsson K. Fracture risk assessment: State of the art, methodologically unsound, or poorly reported? Curr Osteoporos Rep 2012;10:199-207.

5. Editor as author in own journal. London (UK): Committee on Publication Ethics); 2005. Available: publicationethics.org /case/editor-author-own-journal (accessed 2013 Jan. 16).

6. Seife C. Is drug research trustworthy? The pharmaceutical industry funnels money to prominent scientists who are doing research that affects its products - and nobody can stop it. Sci Am 2012;307:56-63. 
7. Kanis JA, Johnell O, Oden A, et al. FRAX and the assessment of fracture probability in men and women from the UK. Osteoporos Int 2008:19:385-97.

8. Grigorie D, Sucaliuc A, Johansson H, et al. Incidence of hip fracture in Romania and the development of a Romanian FRAX model. Calcif Tissue Int 2013;92:429-36.

9. Guide for WHO collaborating centres. Geneva (Switzerland): World Health Organization; 2012. Available: www.who.int /collaboratingcentres/information/en/ (accessed 2013 Jan. 17).

10. Clinician's guide to prevention and treatment of osteoporosis. Washington (DC): National Osteoporosis Foundation; 2008 [revised 2010]. Available: http://nof.org/files/nof/public/content /file/344/upload/159.pdf (accessed 2013 Nov. 29).

11. Donaldson MG, Cawthon PM, Lui LY, et al. Estimates of the proportion of older white women who would be recommended for pharmacologic treatment by the new U.S. National Osteoporosis Foundation Guidelines. J Bone Miner Res. 2009;24:675-80.

Competing interests: Teppo Järvinen has received grants from the Sigrid Juselius Foundation, the Competitive Research Fund of the Pirkanmaa Hospital District and the Academy of Finland, as well as reimbursement of travel expenses from Synthes Finland Oy, all for work unrelated to the topic of this commentary. Pierre Guy has recevied grants from the Canadian Institutes of Health Research, the Natural Sciences and Engineering Research Council of Canada, the Canadian Foundation for Innovation and the British Columbia Medical Association (BCMA) for work unrelated to the topic of this commentary. He has also received fees from the BCMA (for a provincial quality improvement project on redesign of hip fracture care) and from Stryker Orthopedics (as a product development con- sultant). He is a board member and shareholder in Traumis Surgical Systems Inc. and a board member for the Canadian Orthopedic Foundation. He also serves on the speakers' bureaus of AO Trauma North America and Stryker Canada. No other competing interests declared.

Affiliations: Department of Orthopaedics and Traumatology (Järvinen), Helsinki University Central Hospital, Helsinki, Finland; Department of Surgery (Jokihaara), Kanta-Häme Central Hospital, Hämeenlinna, Finland; Centre for Hip Health and Mobility and Division of Orthopedic Trauma (Guy), Department of Orthopedics, University of British Columbia, Vancouver, B.C.; Iberoamerican Cochrane Center (Alonso-Coello), Biomedical Research Institute Sant Pau (IIB Sant Pau), Barcelona, Spain; Centre for Statistics in Medicine (Collins), Botnar Research Centre, University of Oxford, Oxford, UK; Department of Surgical Sciences (Michaëlsson), Section of Orthopaedics, Uppsala University, Uppsala, Sweden; the Bone Research Group (Sievänen), The UKK Institute for Health Promotion Research, Tampere, Finland

Contributors: Teppo L.N. Järvinen conceptualized the analysis and, with Harri Sievänen, wrote and revised the manuscript. All other authors provided substantive input on drafts of the manuscript. All authors have seen and approved the final version of the manuscript.

Acknowledgements: We thank Dr. Pekka Kannus for his comments on the manuscript and Virginia Mattila MA, for linguistic expertise and language revisions.

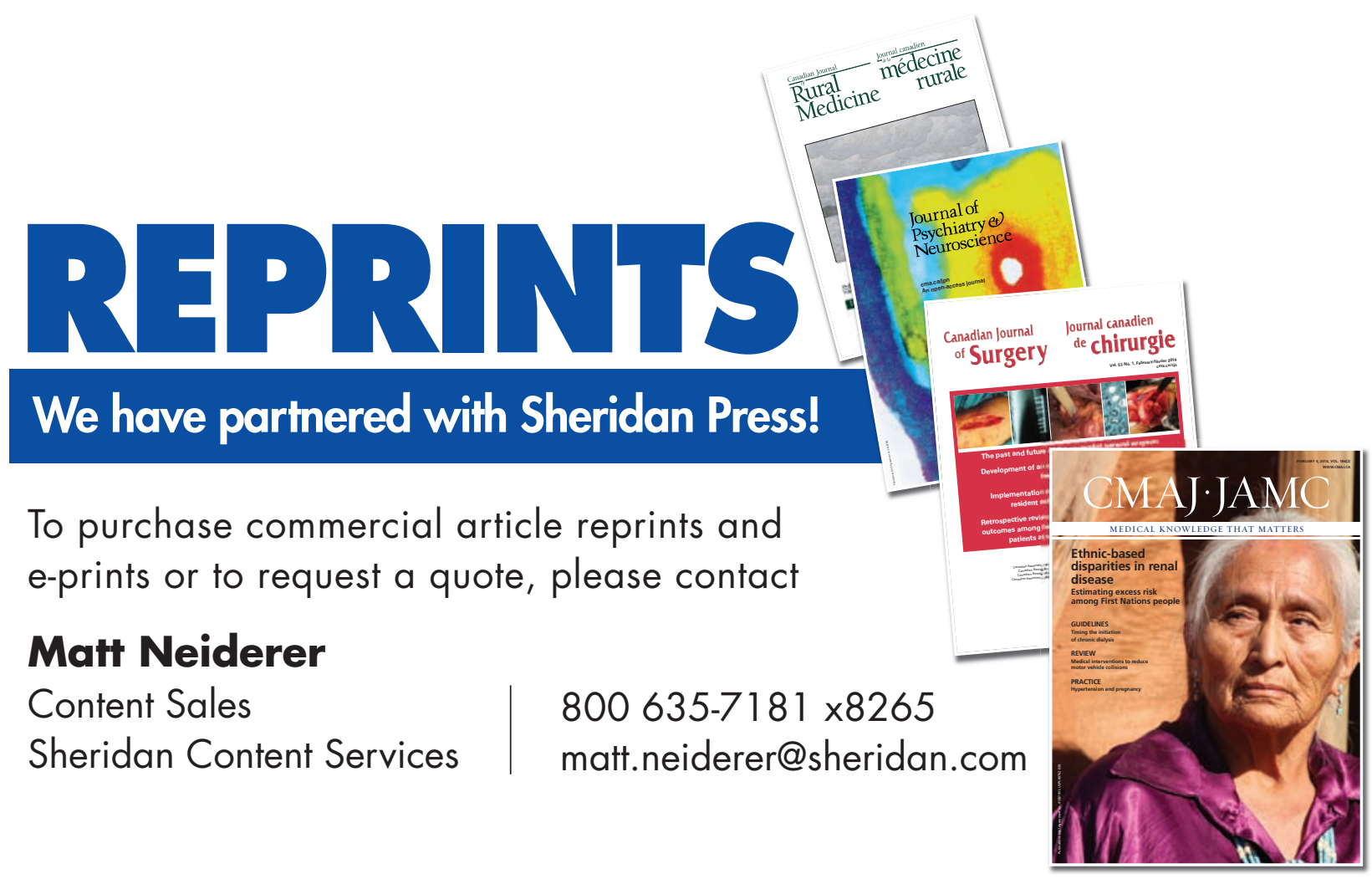

